\title{
Green Synthesis and Characterization of Silver Nanoparticles Using Vitex negundo (Karu Nochchi) Leaf Extract and its Antibacterial Activity
}

\section{Anandalakshmi $\mathrm{K}^{1}$ and Venugobal $\mathbf{J}^{2^{*}}$}

${ }^{1}$ Department of Physics, Periyar Government Arts and Science College, Cuddalore, Tamil Nadu, India

${ }^{2}$ Department of Physics, Sir Issac Newton Engineering College and Technology, Nagapattinam, Tamil Nadu, India

\begin{abstract}
The present paper focuses on the synthesis of silver nanoparticles using with different leaf extract concentrations of Vitex negundo. The biosynthesized nanoparticles were characterized by UV-vis absorption spectrophotometry, fourier transform infrared spectroscopy, X-ray diffraction, field emission scanning electron microscopy, energy dispersive X-ray, atomic force microscopy, transmission electron microscopy, photoluminescence and zeta potential techniques. The formation of silver nanoparticles was confirmed by the surface plasmon resonance absorption peak at $423 \mathrm{~nm}$ in UV-vis absorption spectra of the synthesized silver nanoparticles. The fourier transform infrared spectroscopy indicates flavonoids as a potential reduced agents. Field emission scanning electron microscopy shows the synthesized silver nanoparticles are in spherical shape. Energy dispersive X-ray spectroscopy shows the strong peak belongs to silver, and it confirms the formation of Ag NPs. X-ray diffraction spectra of synthesized silver nanoparticles exhibit they are in face centered cubic crystalline structure. The photoluminescence spectra of synthesized silver nanoparticles show their emission peak at 489-481 nm and the emission intensity is proportional to the different concentrations of leaf extract. The spherical shaped silver nanoparticles are observed by atomic force microscopy technique. The zeta potential value is observed at $-13.5 \mathrm{mV}$, which shows the synthesized silver nanoparticles are incipient instability. The antimicrobial activity of the synthesized nanoparticles is studied using the disc diffusion method, which indicates that both Gram positive and Gram negative microorganisms have been affected by the silver nanoparticles. The observed antibacterial activity could be find important applications in medicine, biology and industry.
\end{abstract}

Keywords: Silver nanoparticles; Vitex negundo; Surface plasmon resonance; Face centered cubic; Atomic force microscopy; Antibacterial activity

\section{Introduction}

Nanoparticles, generally considered as particles with a size up to $100 \mathrm{~nm}$, exhibit completely new or improved properties as compared to the bulk material that they are collected based on particular characteristics such as size, distribution and morphology [1]. Recent developments in nanoscience and nanotechnology have brought potential building blocks for electronic, optoelectronics, medicines and solar cells [2]. Nanoparticles of noble metals, such as gold, silver and platinum are broadly applied in many fields and also directly come in contact with the human body, such as shampoos, soaps, detergents, shoes, cosmetic products, and tooth paste, besides medical and pharmaceutical applications [3]. In present days, nanoparticles based on their electrical, optical, magnetic, chemical and mechanical properties are used in various areas, such as the medical sector for diagnosis, antimicrobial, drug delivery and also they are also used in the electronic and optoelectronic industry $[4,5]$ in the chemical sector for catalysis [6] for environmental protection [7] and energy conversion [8].

Nanoparticle synthesis is generally carried out by a variety of physical and chemical methods, such as laser ablation, pyrolysis, chemical or physical vapour deposition, lithography electrodeposition, sol gel etc., which are not eco friendly [9]. The preparation of nanoparticles such as $\mathrm{ZnO}, \mathrm{CdO}, \mathrm{NiO}, \mathrm{Sm}_{2} \mathrm{O}_{3}$ are reported by many researchers [10-13]. Although the commercial methodologies have proven as efficient tools for synthesizing, but their continuous use may pose a great threat to human health and the environment because of the use of toxic and hazardous reagents and generation of toxic byproducts in some instances [14]. When compared to various physical and chemical methods, the synthesis is low cost, competent and fast method for producing nanoparticles. Now-a- day, green chemistry procedure are generally used in various biological systems such as yeast, fungi, bacteria and plant extract for synthesis of silver nanoparticles (Ag NPs) [15-17]. The main reason for selection of the green synthesis method is, due its low cost, non-toxic, eco-friendly and also has great advantages. The green synthesised method is utilized to synthesis for Ag NPs using the various leaf extracts [18-21].

Vitex negundo Linn belongs to the family of verbanaceae, which is commonly known as chase tree and also called as Karu Nochi in Tamil, Nirgundi in Hindi. It is a large shrub grown in waste lands throughout India. It is one of the common plants used in traditional medicine and reported to have variety of biological and pharmacological applications [22].

Although, all parts of $V$. negundo are in medicine, its leaves have the most potential for medicinal value especially in for treatment of eye-disease, tooth ache inflammation, leucoderma, enlargement of the spleen, skin-ulcers, in catarrhal fever, rheumatoid arthritis, gonorrhoea and bronchitis, anti-bacterial, anti-pyretic, anti-inflammatory, antioxidant and anti-histaminic agents [23].

The present work the Ag NPs are synthesized by green synthesis method using the Vitex negundo leaf extract. The synthesized Ag

*Corresponding author: Venugobal J, Department of Physics, Sir Issac Newton Engineering College and Technology, Nagapattinam-611 102, Tamil Nadu, India, Tel: +919047553277; E-mail: venuphy@yahoo.com

Received July 19, 2017; Accepted July 25, 2017; Published July 31, 2017

Citation: Anandalakshmi K, Venugobal J (2017) Green Synthesis and Characterization of Silver Nanoparticles Using Vitex negundo (Karu Nochchi) Lea Extract and its Antibacterial Activity. Med Chem (Los Angeles) 7: 218-225. doi: 10.4172/2161-0444.1000460

Copyright: () 2017 Anandalakshmi K, et al. This is an open-access article distributed under the terms of the Creative Commons Attribution License, which permits unrestricted use, distribution, and reproduction in any medium, provided the original author and source are credited. 
NPs are characterized by UV-vis, Photo luminescence (PL), X-ray diffraction (XRD), Fourier transform infrared spectroscopy (FTIR), Field scanning electron microscopy (FESEM), Energy dispersive X-ray (EDAX), Atomic force microscopy (AFM), Transmission electron microscopy (TEM), Zeta potential. The obtained results are presented and discussed in details.

\section{Materials and Methods}

\section{Materials}

Silver nitrate $\left(\mathrm{AgNO}_{3}\right)$ (AR grade) was purchased from Sigma Aldrich chemicals. Vitex negundo (Karu nochchi) was collected from Kollidam located in Tamil Nadu, India. Pure culture of Gram negative and Gram positive bacteria were collected from National Chemical Laboratory, Pune, India. The microbial cultures were maintained by the Department of Pharmacy, Annamalai University, Annamalai Nagar, Tamil Nadu, India.

\section{Preparation of leaf extract}

Fresh leaves of Vitex negundo were collected, then washed thoroughly with distilled water several times to remove the dust and dried under shade. The dried leaves were cut into small pieces and ground to powder. This $5 \mathrm{~g}$ of Vitex negundo leaf powder was boiled in $100 \mathrm{~mL}$ of distilled water at $80^{\circ} \mathrm{C}$ for 10 mins and filtered in whatman No: 1 filter paper. Finally, the prepared extract solution was cooled at $4^{\circ} \mathrm{C}$ and stored for further synthesis of nanoparticles.

\section{Synthesis of silver nanoparticles}

$10 \mathrm{~mL}$ of $1 \mathrm{mM}$ aqueous solution of silver nitrate $\left(\mathrm{AgNO}_{3}\right)$ was taken. Then the prepared leaf extract solution with various concentrations from 1, 2, 3, 4 and $5 \mathrm{~mL}$ was added separately to it at room temperature. After $20 \mathrm{~min}$, the solution was turned from light yellow to dark brown colour indicating the formation of Ag NPs.

\section{Characterization techniques}

UV-vis spectroscopy is the most important technique and simplest way to confirm the formation of nanoparticles. Absorbance spectra of colloidal sample was taken in the range of 800 to $200 \mathrm{~nm}$, with the help of UV-vis spectrometer SHIMADU-UV 1800 with distilled water as a reference. FTIR analysis was performed for leaf extract and silver nanoparticles using FTIR RX1-Perkin Elmer in the wave length range 4000 to $400 \mathrm{~cm}^{-1}$. The emission spectra were recorded using a LF-45 fluorescence spectrophotometer (Perkin Elmer). The X-Ray Diffraction (XRD) analysis for silver nanoparticles was performed by XPERT-PRO using monochromatic $\mathrm{Cu}$ ka radiation $\left(\lambda=1.5406 \mathrm{~A}^{\circ}\right)$ operated at $40 \mathrm{kV}$ and $30 \mathrm{~mA}$ at $2 \theta$ angle pattern. The morphology and shape of the silver nanoparticles were examined using Field emission electron microscopy SUPRA55 (CARL ZEISS, Germany). EDAX analysis of silver nanoparticles was performed on a SUPRA55 (CARL ZEISS, Germany) using FESEM equipped with an EDAX attachment. Sample preparation for FESEM analysis is as follows: The surface of the sample has been stubbed using the double-side adhesive carbon tape and sample are coated with the help of gold coater and deposited with thin layer gold (heavy metal) on the sample. The stability of Ag NPs is studied by Zeta potential measurements using Malvern instruments. The surface topological studies were carried out using Atomic force Microscope (Nano surf Easy scan 2) AGILENT-N9410A-5500. Silver nanoparticles films deposited on glass slides by spin coating for AFM characterization. The morphology and size of silver nanoparticles were through Transmission Electron Microscope (JEM2100). For sample preparation for TEM analysis, the dilute drops of suspension were allowed to dry slowly on carbon-coated grids for TEM measurement.

\section{Antibacterial activity}

Antibacterial activity of the synthesised Ag NPs was studied by the standard disc diffusion method. The overnight grown bacterial suspensions of Escherichia coli (ATCC 8739), Klebsiella pneumoniae (ATCC 10031), Micrococcus flavus (ATCC 25619), Pseudomonas aeruginosa (ATCC 25619), Bacillus subtilis (ATCC 6633), Bacillus pumilus (ATCC 12228), Staphylococcus aureus (ATCC 29737) were standardized using Mc farland standard. $5 \mathrm{~mm}$ diameter discs of whatman filter paper (No: 1). The dilutions of biosynthesised Ag NPs varying from $5 \mathrm{mg}, 10 \mathrm{mg}$ and $15 \mathrm{mg} / \mathrm{mL}$ were prepared with two fold symmetry. $20 \mathrm{~mL}$ of molten sterilized nutrient agar solution was poured into each petri plates and seven organisms were grown in them. The tested organisms were inoculated in four discs $(5 \mathrm{~mm}$ diameter), which is dipped in different dilutions of Ag NPs (5 mg, 10 $\mathrm{mg}$ and $15 \mathrm{mg} / \mathrm{mL}$ ) solutions, and another disc was dipped in $2 \mathrm{mg} /$ $\mathrm{mL}$ of antibiotic Ofloxcin. Each petri plate was loaded with four discs. The plates containing the bacteria and $\mathrm{Ag} N P s$ were incubated at $37^{\circ} \mathrm{C}$, and then examined for confirmation appears as a clear area around the disc. The diameter of such zones of inhibition was measured using a metre ruler, and the mean value for each organism was recorded and expressed in millimeters.

\section{Results and Discussion}

\section{Optical studies}

The aqueous silver nitrate and leaf extract of UV-vis spectrum are shown in Figure 1. From the $\mathrm{AgNO}_{3}$ solution neither creates the colour nor displayed the characteristic broad peaks. Aqueous extract solution and addition with prepared silver nitrate solution, the consequent colour changes are observed from light yellow to dark brown within 20 minutes. Nisha et al. reported that Ag NPs shows from colorless to yellowish brown in aqueous solution and it was due to excitation of SPR used lemon peels extracts [24]. Figure 2 shows the UV-vis spectra of aqueous solution of leaf extract at various concentrations ( $1 \mathrm{~mL}, 2 \mathrm{~mL}, 3 \mathrm{~mL}, 4 \mathrm{~mL}$ and $5 \mathrm{~mL}$ ) with $1 \mathrm{mM}$ aqueous $\mathrm{AgNO}_{3}$ solution. The color of $\mathrm{AgNO}_{3}$ solution change when it is added with vitex negundo leaf extracts. After the addition of leaf extract, we have visual perception of change in color of reaction mixture from watery to

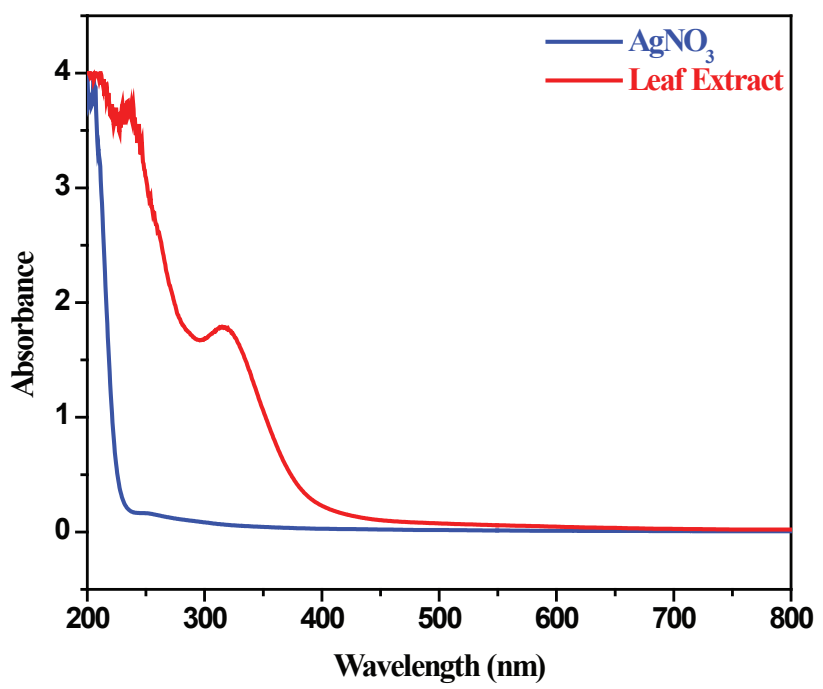

Figure 1: UV-Vis absorption spectra of the $\mathrm{AgNO}_{3}$ and fresh leaf extract. 
yellowish brown indicating the formation of Ag NPs. Its is attributed to the collective oscillation of free conduction electrons result in surface plasmon resonance (SPR) induced by interacting electromagnetic field [25]. Figure 2 shows the SPR peaks for the synthesized Ag NPs for different leaf extract concentrations (1-5 mL) are observed at 452-428 $\mathrm{nm}$, which is characteristic of colloidal silver [26]. It shows that the SPR peak is blue shifted when increasing in leaf extract concentrations. This observed blue shift is due to the reduction Ag NPs size. Moreover, the absorbance of Ag NPs increases when increasing the leaf extract concentrations (Figure 3). As the concentration of leaf extract is increased, size of the particles decrease due to the more number of biomolecules available, which acts as reducing agents. Furthermore, aggregation of nanoparticles may occur due to formation of SPR peak in the higher concentration of leaf extracts. The spectrum can exhibit a shift towards the blue end depending upon the particles size, shape, and state of aggregation and surrounding dielectric medium [27]. The formation of spherical and aggregation of AgNPs are further confirmed by TEM analysis. Narayanan et al. reported the synthesis of Ag NPs size

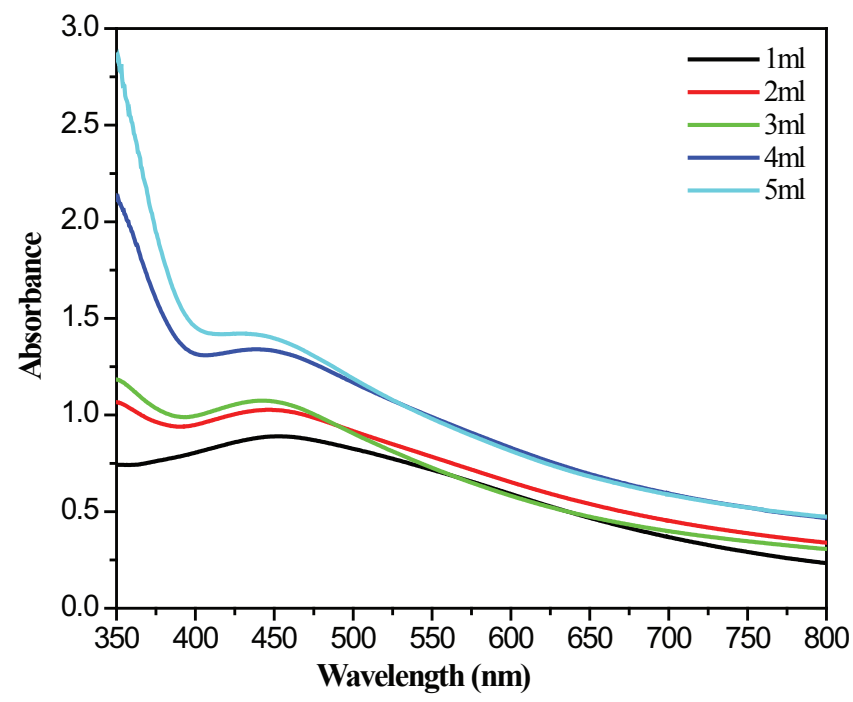

Figure 2: UV-Vis absorption spectra of the Ag NPs synthesized at different quantity of leaf extract with fixed concentrations of $\mathrm{AgNO}_{3}$.

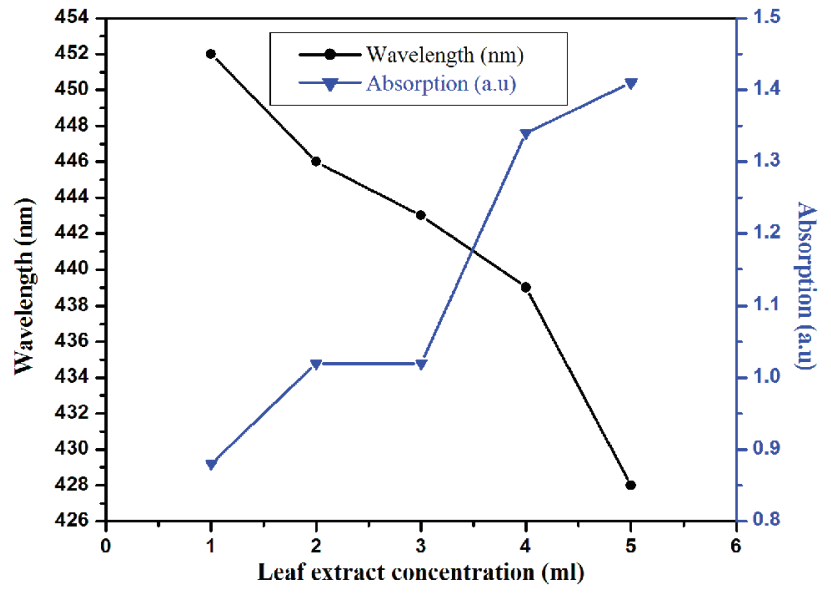

Figure 3: Plot on Leaf extracts concentration Vs Wavelength and absorption. is decreased in the appeared of blue shift in SPR band with increasing in the concentration of extract using Coleus amboinicus Lour leaves [28].

Figure 4 Shows the UV-Vis spectra of synthesized Ag NPs using Vitex negundo leaf extract aqueous solution taken at different time interval. The SPR peak appears at $428 \mathrm{~nm}$ is clearly observed, the intensity of the SPR peak is increased with reaction time $(30 \mathrm{mins}, 1 \mathrm{hr}$, $24 \mathrm{hrs}, 48 \mathrm{hrs}, 72 \mathrm{hrs}$ ). However, the wavelength of SPR peaks does not change. The increase in intensity could be due to increase in number of Ag NPs form as a result of reduction of silver ions present in the aqueous solution. The SPR peak of Ag NPs disappears in a few days or $72 \mathrm{~h}$ of reaction time and Ag NPs are completely vanished [29]. By the above observation we conclude that the intensity of SPR peak increase with the increase in reaction time however, the wavelength maintains same values as shown in the Figure 5.

The optical property of synthesized silver nanoparticles is evaluated using photoluminescence spectroscopy. The synthesized Ag NPs are excited at $370 \mathrm{~nm}$. Increased photoluminescence intensity is observed with an increase of leaf extract quantity shown in Figure 6. The various concentration of leaf extracts $(1,2,3,4$ and $5 \mathrm{~mL})$ that equivalent

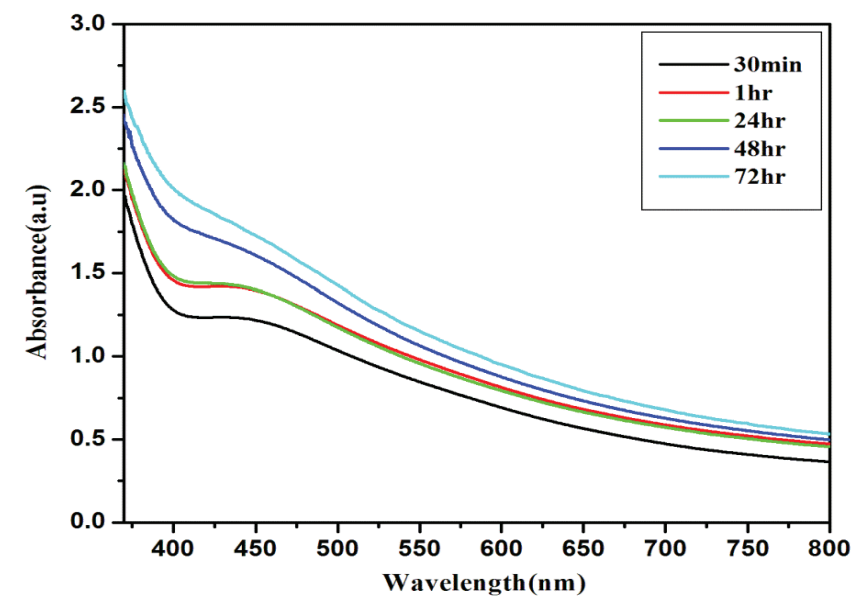

Figure 4: UV-Vis absorption spectra of the Ag NPs synthesized at different time interval (30 mins, $1 \mathrm{hr}, 24 \mathrm{hrs}, 48 \mathrm{hrs}$ and $72 \mathrm{hrs}$ ).

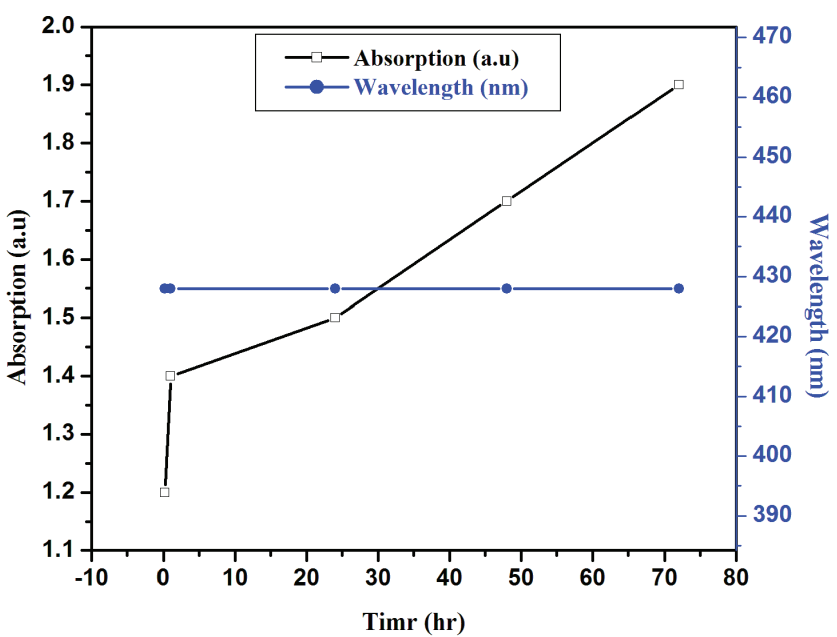

Figure 5: Plot on different time interval Vs absorption and wavelength. 
emission peaks like 489, 487, 486, 484 and $481 \mathrm{~nm}$ are observed. These emission peaks are shifted from higher side to lower side (Blue shift). From the UV-vis analysis the same blue shift are also observed. Above information confirms the synthesis of Ag NPs is decrease in the high concentration $(5 \mathrm{~mL})$ using Vitex negundo leaf extracts.

According to Ajitha et al. reported that fixed excitation wavelength at $370 \mathrm{~nm}$ for different concentration corresponding to PL emission peaks $462,458,453$, and $447 \mathrm{~nm}$ were observed, here blue emission indicated decrease in the particle size [30]. Theoretical work revealed that photoluminescence of silver metals could be viewed as excitation of electrons from occupied d bands into states above the Fermi energy. Subsequently electron-photon and hole-photon scattering process leads to energy loss and finally photo luminescent radiative recombination of Fermi level electrons and occupied sp or d-band with the holes [31-34].

\section{Structural analysis}

The XRD patterns of Vitex negundo leaf extract synthesised Ag NPs are shown in Figure 7. XRD pattern of the synthesized Ag NPs exhibits the face centered cubic structure corresponding to the four reflection peaks are observed with $2 \theta$ values of $38.11^{\circ}, 44.29^{\circ}, 64.45^{\circ}$ and $77.39^{\circ}$ they are indexed to the (111), (200), (220), and (311) crystal planes (JCPDS card no. 89-3722). The XRD peaks intensity of Ag NPs

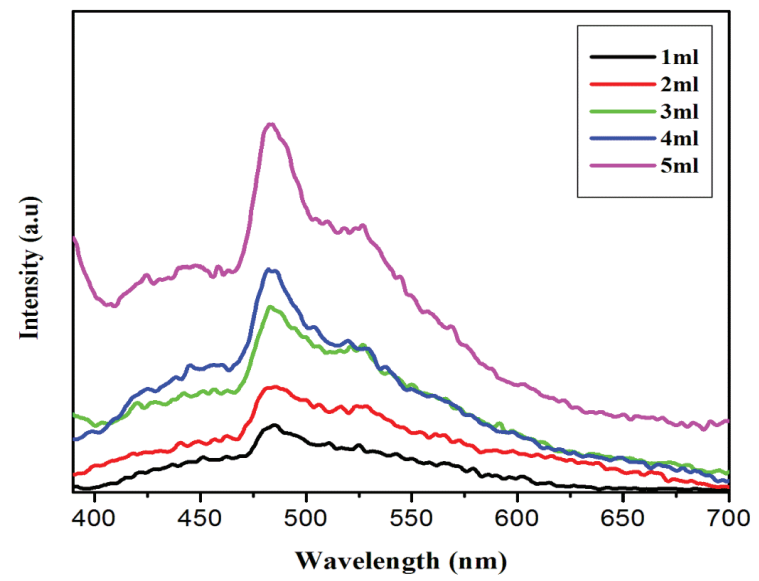

Figure 6: PL spectra of the prepared Ag NPs at different concentration of leaf extract.

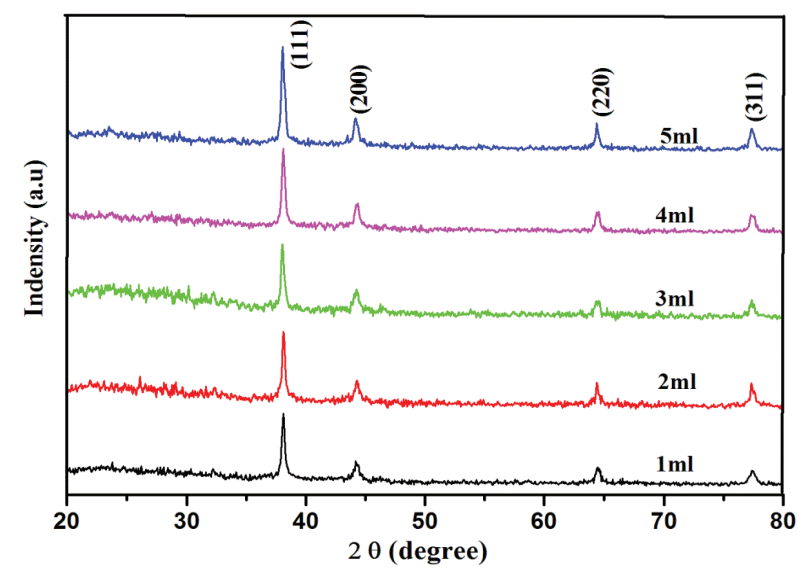

Figure 7: XRD diffraction pattern of the Ag NPs prepared in different concentrations of Vitex negundo leaf extract quantity. increases when increasing the leaf extract concentration $(1-5 \mathrm{~mL})$. From the Table 1, It is observed that the decrease in crystalline size with increase of concentration and increase in the strain.

The average crystal size of the silver nanoparticles is calculated from FWHM of the diffractions peaks using Scherrer's equation:

\section{$\mathrm{D}=\mathrm{k} \lambda / \beta \cos \theta$}

Where, $\mathrm{D}$ is particle size, $\mathrm{k}$ is the Scherrer's coefficient (0.9), $\lambda$ is wavelength of X-ray source $(1.5406 \mathrm{~nm}), \beta$ is the full width at half maximum (FWHM) and $\theta$ is the diffraction angle. The silver nanoparticles size is calculated in the range of 35 to $20 \mathrm{~nm}$ for different concentration of leaf extracts (1-5 mL). The absence of other diffraction peaks present in XRD pattern is observed, which indicates that the synthesized Ag NPs are essentially pure. Similar results were reported in silver nanoparticles using artemisia annua extract [35]. From the observation Table 1, it is clearly understood that $5 \mathrm{~mL}$ leaf extract concentration is more suitable for synthesis small size Ag NPs. Therefore, this higher concentration of Ag NPs is used for further studies.

\section{Fourier Transform Infrared Spectroscopy (FTIR)}

The FTIR spectrum of the extract gives information of the functional groups involved in the reduction of the silver ions. The FTIR study identifies the minerals that capped on silver nanoparticles and some possible biomolecules from Vitex negundo leaf extract are changes from $\mathrm{Ag}^{+}$to $\mathrm{Ag}^{0}$. The FTIR spectra of (Figure 8a) aqueous leaf extract and (Figure 8b) synthesised Ag NPs are analysis shown in Figure 7. The FTIR spectrum shows strong peaks at (567 and 485 $\left.\mathrm{cm}^{-1}\right),\left(604\right.$ and $\left.620 \mathrm{~cm}^{-1}\right),\left(772\right.$ and $\left.789 \mathrm{~cm}^{-1}\right),\left(1049\right.$ and $\left.1098 \mathrm{~cm}^{-1}\right)$, (1380 and $\left.1383 \mathrm{~cm}^{-1}\right),\left(1604\right.$ and $\left.1603 \mathrm{~cm}^{-1}\right),\left(3374\right.$ and $\left.3324 \mathrm{~cm}^{-1}\right)$,

\begin{tabular}{|c|c|c|c|c|}
\hline $\begin{array}{c}\text { Concentration } \\
(\mathbf{m l})\end{array}$ & $\begin{array}{c}\text { Average NPs } \\
\text { size }(\mathbf{n m})\end{array}$ & $\begin{array}{c}\text { Lattice } \\
\text { parameter }(\mathbf{A})\end{array}$ & $\begin{array}{c}\text { Cell volume } \\
\left(\AA^{3}\right)\end{array}$ & Micro strain \\
\hline $1 \mathrm{~mL}$ & 35.96 & 4.0877 & 68.3125 & 0.0024 \\
\hline $2 \mathrm{~mL}$ & 28.64 & 4.0863 & 68.2361 & 0.0022 \\
\hline $3 \mathrm{~mL}$ & 25.76 & 4.0852 & 68.1799 & 0.0031 \\
\hline $4 \mathrm{~mL}$ & 23.50 & 4.0858 & 68.2074 & 0.0036 \\
\hline $5 \mathrm{~mL}$ & 20.91 & 4.0875 & 68.2941 & 0.0055 \\
\hline
\end{tabular}

Table 1: The variation of Crystallite size, Lattice parameter, Cell volume and Micro strain value of bio synthesised nanoparticle.

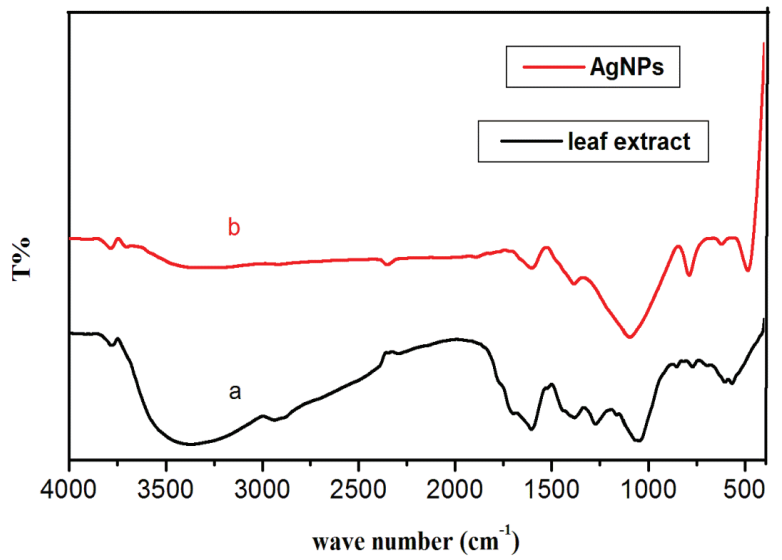

Figure 8: FTIR spectrum of the (a) Vitex negundo leaf extract (b) synthesised silver nanoparticles using Vitex negundo leaf extract. 
(3781 and $3783 \mathrm{~cm}^{-1}$ ) respectively. The strong band at (567 and 485 $\mathrm{cm}^{-1}$ ) corresponded to $\mathrm{NO}_{2}$ in deformation aromatic nitro compound and $\mathrm{C}-\mathrm{O}=\mathrm{O}$ carboxylic group in bending vibration. The weaker band at $\left(604\right.$ and $\left.620 \mathrm{~cm}^{-1}\right),\left(772\right.$ and $\left.789 \mathrm{~cm}^{-1}\right)$ corresponds $\mathrm{C}-\mathrm{Cl}$ stretching vibration in alkyl group. The strong peak at $\left(1049\right.$ and $\left.1098 \mathrm{~cm}^{-1}\right)$ is due to $\mathrm{C}-\mathrm{O}$ stretching vibration in carboxylic group and flavanones. The characterized peak is observed at $\left(1380\right.$ and $\left.1383 \mathrm{~cm}^{-1}\right) \mathrm{C}-\mathrm{N}$ stretching vibration in amine group [36]. The strong band at (1604 and 1603 $\mathrm{cm}^{-1}$ ) aromatic $\mathrm{C}=\mathrm{C}$ bending vibration [37]. The broad band at $(3374$ and $\left.3324 \mathrm{~cm}^{-1}\right),\left(3371\right.$ and $\left.3783 \mathrm{~cm}^{-1}\right)$ are $\mathrm{OH}$ stretching vibration in alcohols. Some peaks appeared in the FT-IR spectrum of leaf extract, which were disappeared in FT-IR spectra of green synthesized Ag NPs. This disappeared peaks indicates the phytochemical present in the leaf extract, which is involved in reduction of silver nanoparticles.

The phytochemical present in the leaf extract such as Flavonoids [38-40] iridoids [41-43], terpenes [44,45], and steroids [46] are the major classes of compounds isolated from this plant. Terpenoids are poorly water-soluble and hence may not be among prime moieties involved in the bioreduction reaction. However, proteins seem to exhibit little importance in biosynthesis of nanoparticles and also water-soluble phenolic acid and flavonoid compounds are believed to play a major role in bioreduction reaction. But, the possible mechanism is still unclear and needs further investigation [47].

In addition, carboxylate group can act as surfactant to attach on the surface of nanoparticles and results in Ag NPs stabilization [48]. Noruzi et al. and Kalpana et al. suggested that synthesis of Au NPs using Rosa hybrid petal extract in the presence of protein act as the reducing and stabilizing agent $[49,50]$. The carboxylic group and hydroxyl group are also responsible for reduction of silver ion into silver nanoparticles. It was proved by Raja et al., Kumar et al. and Jayaseelan et al. [51-53]. Shankar et al. suggested that the presence of flavonanes or terpenoids adsorbed on the surface of the synthesized metal nanoparticles and the reaction of metal ions which was possibly facilitated by the reducing sugars and/or terpenoids present in the neem leaf broth [54]. In the present work synthesised Ag NPs, flavonoids and Carboxylic group act as a reducing and stabilizing agent in Vitex negundo leaf extracts.

\section{Morphological studies}

Figure 9 shows, different magnification of FE-SEM images of the green synthesized silver nanoparticles using Vitex negundo leaf extract. It shows that the synthesized Ag NPs are in spherical shape. Furthermore, the particle size is observed to be $20-35 \mathrm{~nm}$.

The energy dispersive X-ray analysis (EDAX) is shown in Figure 10 EDAX spectrum shows that the strong silver peak (3kev) along

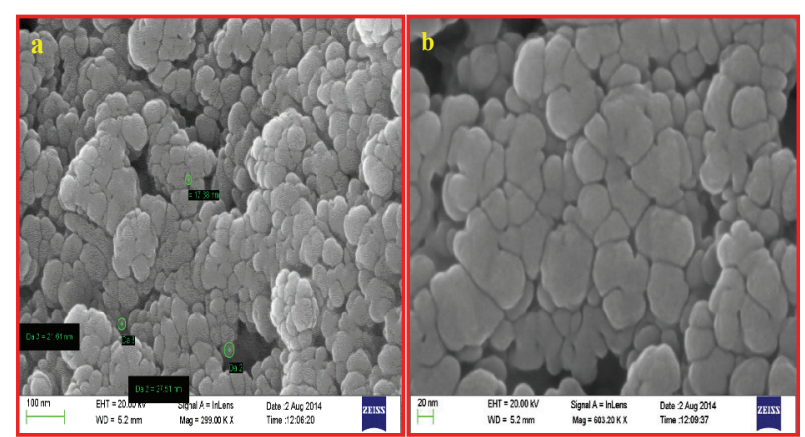

Figure 9: FESEM images of the synthesised Ag NPs (a) $100 \mathrm{~nm}$ and (b) $20 \mathrm{~nm}$ magnification respectively. with magnesium, chloride, oxygen, carbon and potassium elements small peaks. Similar result observed from EDAX spectrum by other researchers $[55,56]$. Qualitative as well as quantitative information of green synthesized silver nanoparticle is shown in Figure 10.

Figure 11 shows the surface morphology of the Ag NPs was studied by atomic force microscopy. AFM images shows the synthesized Ag NPs are in spherical shape.

TEM images of silver nanoparticles with various magnifications as shown in the Figure 12a-12c. The images reveal that formation of spherical shape less aggregated silver nanoparticles. In addition, the average size of silver nanoparticles is $23 \mathrm{~nm}$, which can be seen observed from particles size distribution histogram image derived from the TEM images. The size of the Ag NPs is obtained from TEM $(23 \mathrm{~nm})$ is consistent with XRD study $(20 \mathrm{~nm})$. Figure $12 \mathrm{~d}$ shows the crystallinity of the silver nanoparticles, which are by selected area emission diffraction (SAED). SAED pattern of the synthesized Ag NPs exhibits the dotted concentric rings belong to (111), (200), (220) and (311) planes, which matches with the result of XRD analysis.

\section{Zeta potential measurement}

As shown in Figure 13 the Ag NPs obtain have a negative zeta potential value. Zeta potential is a basic parameter for classification of stability in aqueous Ag NPs suspensions. The Zeta potential measurements of the biosynthesised Ag NPs show a sharp peak at -13.5 $\mathrm{mV}$ indicative of that the surface of the nanoparticles is negatively charged. Generally, the zeta potential of the nanoparticles should be either highest than $+30 \mathrm{mV}$ on lower than $-30 \mathrm{mV}$ [57,58]. But, the synthesized Ag NPs by Vitex negundo shows incipient instability.

\section{Antibacterial activity}

To estimate the antibacterial effect of Ag NPs, they are tested against seven different bacterial species at different concentration in

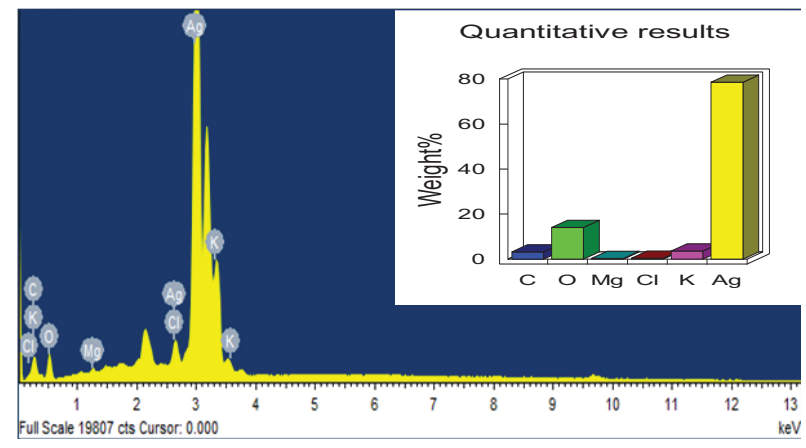

Figure 10: EDAX spectrum of the Ag NPs and quantative result (inset figure)

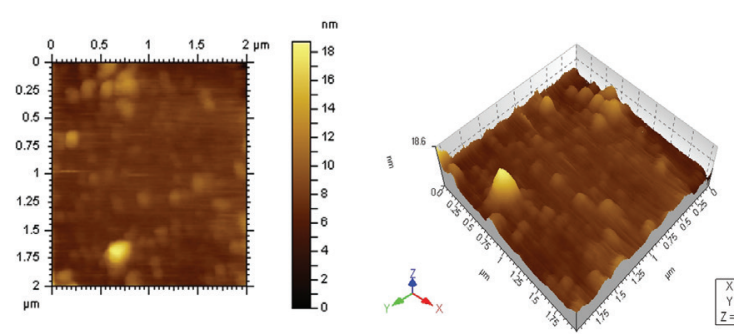

Figure 11: AFM image of $2 D$ and $3 D$ view of green synthesized silver nanoparticles. 


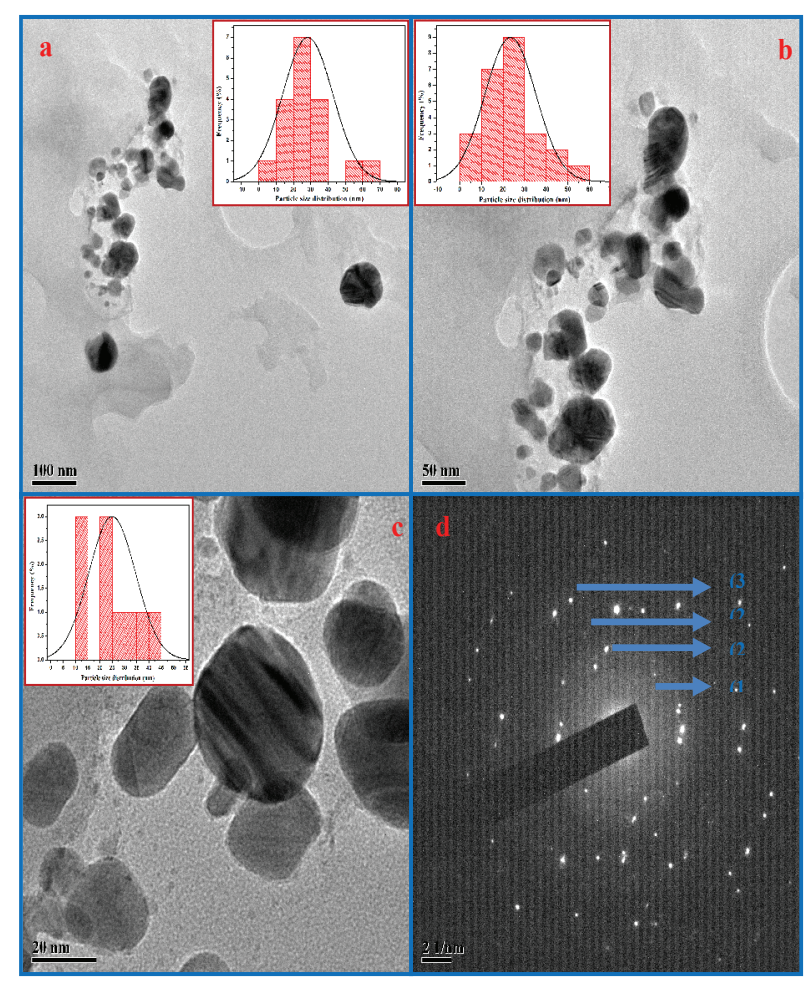

Figure 12: (a-c) TEM image of green synthesised silver nanoparticles in different magnification and particle size histogram (inset figure). (d) SAED patterns of silver nanoparticles.

\begin{tabular}{|c|c|c|c|c|}
\hline \multicolumn{5}{|l|}{ Results } \\
\hline & & Mean $(\mathrm{mV})$ & Area (\%) & Width $(\mathrm{mV}$ \\
\hline Zeta Potential $(\mathrm{mV}):-13.5$ & Peak 1: & -13.5 & 100.0 & 6.10 \\
\hline Zeta Deviation (mV): 6.10 & Peak 2: & 0.00 & 0.0 & 0.00 \\
\hline Conductivity $(\mathrm{mS} / \mathrm{cm}): 1.22$ & Peak 3: & 0.00 & 0.0 & 0.00 \\
\hline Result quality : Good & & & & \\
\hline
\end{tabular}

Zeta Potential Distribution

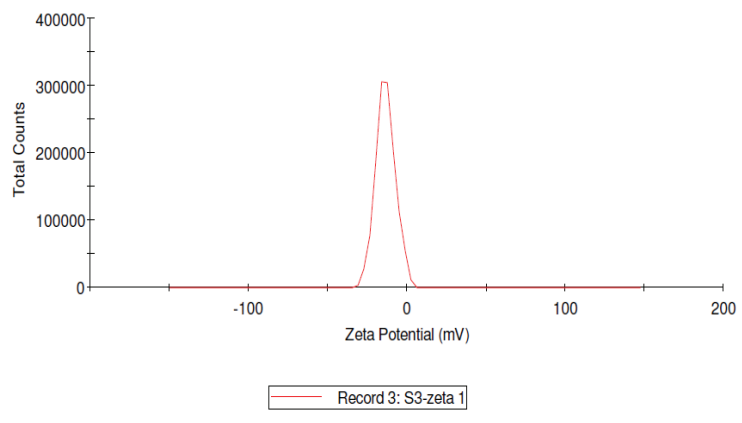

Figure 13: Zeta potential spectrum of the prepared Ag NPs.

this study. The present case, the antibacterial activity of synthesised Ag NPs are tested against microorganism, that is, Gram negative E. coli, P. aeruginosa, K. pneumonia, and Gram positive M. flavus, B. subtilis, B. pumilus, $S$. aureus at different concentrations $(5,10,15 \mathrm{mg} / \mathrm{mL})$ using the disc diffusion method (Table 2). The antibiotic ofloxacin is used as a standard in this study. The antibacterial activity is shown in Figure 14. The Figure 14 and Table 2 indicate the good antibacterial activity in silver nanoparticle using Vitex negundo leaf extract. The potential antibacterial effect of the Ag NPs, E. coli culture is treated

\begin{tabular}{|c|c|c|c|c|}
\hline & \multicolumn{4}{|c|}{ Zone of inhibition of Ag NPs (mm) } \\
\hline Bacterium name & $\begin{array}{c}\text { Control (Ofloxcin) } \\
\mathbf{2} \mathbf{~ m g / m L}\end{array}$ & $\mathbf{5 ~} \mathbf{~ m g / m L}$ & $\mathbf{1 0 ~} \mathbf{~ g / m L}$ & $\mathbf{1 5} \mathbf{~ m g / m L}$ \\
\hline Escherichia coli & 28.5 & 8 & 8 & 9 \\
\hline Klebsiella pneumonia & 18 & 9 & 7.5 & 9.5 \\
\hline Micrococcus flavus & 18.5 & 13 & 9.5 & 10 \\
\hline $\begin{array}{c}\text { Pseudomonas } \\
\text { aeruginosa }\end{array}$ & 22 & 7 & 6.5 & 8 \\
\hline Bacillus subtilis & 22 & 10 & 9 & 11 \\
\hline Bacillus pumilus & 20 & 6 & 10.5 & 9.5 \\
\hline Staphylococcus aureus & 22 & 8.5 & 10 & 10 \\
\hline
\end{tabular}

Table 2: Antibacterial activity of the silver nanoparticle.

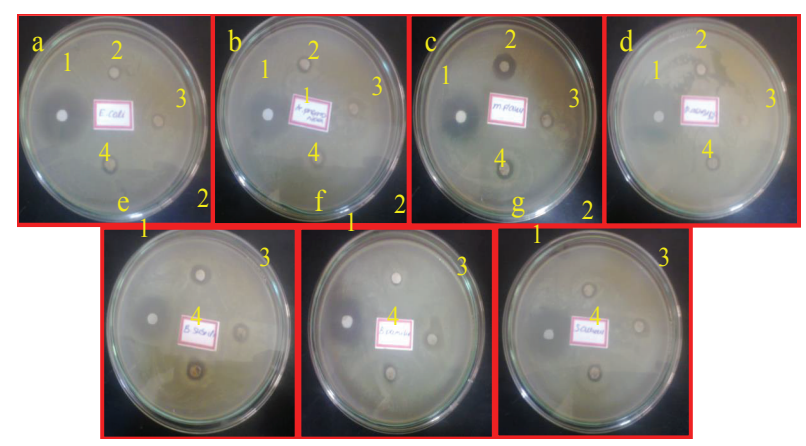

Figure 14: The antibacterial activity of Ag NPs in (a) Escherichia coli (b) Klebsiella pneumonia, (c) Micrococcus flavus, (d) Pseudomonas aeruginosa, (e) Bacillus subtilis, (f) Bacillus pumilus, (g) Staphylococcus aureus at various concentrations ((1) Positive control, (2) $5 \mathrm{mg} / \mathrm{mL}$, (3) 10 $\mathrm{mg} / \mathrm{mL}$ and (4) $15 \mathrm{mg} / \mathrm{mL}$ ).

with Ag NPs effect on the growth pattern of bacteria is analyzed, which has high value in $15 \mathrm{mg} / \mathrm{mL}$ compare with other value. K. pneumonia culture is treated with Ag NPs at high concentration $15 \mathrm{mg} / \mathrm{mL}$ have large area inhibition of bacteria. M. flavus culture is tested with Ag NPs growth pattern of bacterial high value is observed in low concentration $5 \mathrm{mg} / \mathrm{mL}$. P. aeruginosa culture is treated with $\mathrm{Ag} \mathrm{NPs}$ at a high concentration $15 \mathrm{mg} / \mathrm{mL}$ and the good effect of the bacteria. B. subtilis culture is against Ag NPs at a high concentration (wt. \%) $15 \mathrm{mg} / \mathrm{mL}$ is best antibacterial activity comparing with other concentration. B. pumilus culture is treated with Ag NPs at a low concentration 10 $\mathrm{mg} / \mathrm{mL}$ is large area death of bacteria in particle. S. aureus culture is treated with $\mathrm{Ag}$ NPs at $10 \mathrm{mg} / \mathrm{mL}$ and $15 \mathrm{mg} / \mathrm{mL}$ concentration has same effect on the growth pattern of bacterial and it is analyzed. Bindhu et al. reported the beetroot extract mediated Ag NPs revealed efficient antibacterial activity towards the test pathogenic bacteria like Escherichia coli, Pseudomonas aeruginosa and Staphylococcus aureus. The Staphylococcus has maximum zone inhibition and E. coli had minimum zone inhibition and no zone of inhibition was observed for control [27]. Mehmood et al. suggested that the antibacterial activity of synthesized Ag NPs (using Melia azedarach leaf extract) against the five tested bacteria such as E. coli, K. peumonia, S. aureus, $P$. aeruginosa and Proteus $s p$ at different concentration. S. aureus had higher antibacterial activity compare to other tested bacteria [59]. Earlier it was reported by Zhang et al., that the effect of Ag NPs tested against pathogens were $E$. coli and S. aureus, S. aureus had less antibacterial effect compared with E. coli [60]. In the present work, M. flavus bactria is the best because the zone of inhibition is high in it.

According to Ruparelia et al., Nano silver is more active towards Gram positive bacterial strain as compared to Gram negative due to the membrane structure which plays as important role [61]. Finally, the 
current study clearly indicate that the synthesised Ag NPs exhibit the zone of inhibition has high value obtained at Gram positive organism of M. flavus and Gram negative organisms of K. pneumonia. Similar result was also observed by earlier worker [25]. Currently silver nanoparticles are widely used in textiles coatings and wood flooring as antibacterial agents. These plant mediated Ag NPs show high antibacterial activity which may be used in these materials.

\section{Conclusion}

Ag NPs using Vitex negundo leaf extract with different concentrations (1-5 mL) were synthesized by green synthesis method. The formation of Ag NPs was confirmed by UV-visible absorption spectroscopic analysis. XRD pattern of Ag NPs confirms the synthesized particles are in face centered cubic crystalline structure and the sizes of Ag NPs are in the range of 35.96-20.91 nm. FESEM, AFM and TEM analyses shows the synthesized Ag NPs is in spherical shape. Moreover, the Ag NPs size for $5 \mathrm{~mL}$ leaf extract concentration is $23 \mathrm{~nm}$ from TEM study. Zeta potential measurement of the synthesized Ag NPs shows incipient instability. The synthesized Ag NPs exhibits the best antibacterial activity on gram-positive and gram-negative bacteria.

\section{References}

1. van den Wildenberg W (2005) Roadmap Report on Nanoparticles. W \& W Espana s.I. Avda. Diagonal 361.

2. Shah AH, Manikandan E, Ahamed MB, Mir DA, Mir SA (2014) Antibacterial and Blue shift investigations in sol-gel synthesized $\mathrm{Cr} \times \mathrm{Zn} 1-\mathrm{x}$ O Nanostructures. J Luminescence 145: 944-950

3. Song JY, Jang HK, Kim BS (2009) Biological synthesis of gold nanoparticles using Magnolia kobus and Diopyros kaki leaf extracts. Process Biochem 44: 1133-1138

4. Parveen S, Misra R, Sahoo SK (2012) Nanoparticles: a boon to drug delivery, therapeutics, diagnostics and imaging. Nanomedicine: Nanotechnology, Biology and Medicine 8: 147-166.

5. Phillips J, Bowen W, Cagin E, Wang W (2011) Electronic and Optoelectronic Devices Based on Semiconducting Zinc Oxide. Comprehensive Semiconductor Science and Technology 6: 101-127.

6. Raveendran Shiju N, Guliants, VV (2009) Recent developments in catalysis using nanostructured materials. Applied Catalysis A: General 356: 1-17.

7. Ju-Nam Y, Lead JR (2008) Manufactured nanoparticles: An overview of their chemistry, interactions and potential environmental implications. Science of the total environment 400: 396-414.

8. Kim K, Jun, B, Kim J, Kim W (2010) Effects of embedding non-absorbing nanoparticles in organic photovoltaics on power conversion efficiency. Solar Energy Materials and Solar Cells 94: 1835-1839.

9. Choi YJ, Park $\mathrm{HH}$ (2011) Direct patterning of $\mathrm{SnO}_{2}$ composite films prepared with various contents of $\mathrm{Pt}$ nanoparticles by photochemical metal-organic deposition. Thin Solid Films 519: 6214-6218.

10. Thema FT, Manikandan E, Dhlamini MS, Maaza M (2015) Green synthesis of ZnO nanoparticles via Agathosma betulina natural extract. Mat Lett 161: 124-127.

11. Thovhogi N, Park E, Manikandan E, Maaza M, GuribFakim A (2016) Physical properties of $\mathrm{CdO}$ nanoparticles synthesized by green chemistry via Hibiscus Sabdariffa flower extract. J Alloys and Compounds 655: 314-320.

12. Thema FT, Manikandan E, GuribFakim A, Maaza M (2016) Single phase Bunsenite $\mathrm{NiO}$ nanoparticles green synthesis by Agathosma betulina natural extract. J Alloys and Compounds 657: 655-661.

13. Sone BT, Manikandan E, GuribFakim A, Maaza M (2015) $\mathrm{Sm}_{2} \mathrm{O}_{3}$ nanoparticles green synthesis via Callistemon viminalis' extract. J Alloys and Compounds 650: 357-362.

14. Venugopal K, Rather HA, Rajagopal K, Shanthi MP, Sheriff K, Illiyas M, Rather RA, Manikandan E, Uvarajan S, Bhaskar M, Maaza M (2017) Synthesis of silver nanoparticles (Ag NPs) for anticancer activities (MCF 7 breast and A549 lung cell lines) of the crude extract of Syzygium aromaticum. J Photochem Photobiol B: Biology 167: 282-289.
15. Kowshik M, Ashtaputre S, Kharrazi S, Vogel W, Urban J, et al. (2003) Extracellular synthesis of silver nanoparticles by a silver-tolerant yeast strain MKY3. Nanotechnology 14: 95-100.

16. Senapati S, Ahmad A, Khan MI, Sastry M, Kumar R (2005) Extracellular biosynthesis of bimetallic Au-Ag alloy nanoparticles. Small 1: 517-520.

17. Shahverdi AR, Minaeian S, Shahverdi HR, Jamalifar H, Asadat Nohi A (2007) Rapid synthesis of silver nanoparticles using culture supernatants of Enterobacteria: A novel biological approach. Process Biochem 42: 919-923.

18. Sanchez GR, Castilla CL, Gomez NB, Garcia A, Marcos R, Erico R (2016) Carmona Leaf extract from the endemic plant Peumus boldus as an effective bioproduct for the green synthesis of silver nanoparticles. Mat Lett 183: 255-260.

19. Ravichandran V, Vasanthi S, Shalini S, Shah SAA, Harish R (2016) Green synthesis of silver nanoparticles using Atrocarpus altilis leaf extract and the study of their antimicrobial and antioxidant activity. Mat Lett 180: 264-267.

20. Raja S, Ramesh V, Thivaharan V (2017) Green biosynthesis of silver nanoparticles using Calliandra haematocephala leaf extract, their antibacterial activity and hydrogen peroxide sensing capability. Arabian J Chem 10: 253-261.

21. Patil Shriniwas $P$, Kumbhar Subhash T (2017) Antioxidant, antibacterial and cytotoxic potential of silver nanoparticles synthesized using terpenes rich extract of Lantana camara L. leaves. Biochem Biophy Reports 10: 76-81.

22. Baral SR, Kurmi PP (2006) A Compendium of Medicinal Plants in Nepal. Pub: Mrs. Rachana Sharma, 281 Maiju Bahal, Chabhil, Kathmandu, Nepal 450-451.

23. Tiwari OP, Tripathi YB (2007) Antioxidant properties of different fractions of Vitex negundo Linn. Food Chem. 100: 1170-1176.

24. Nisha SN, Aysha OS, Nasar Rahaman JS, Vinoth Kumar P, Valli S, et al (2014) Lemon peels mediated synthesis of silver nanoparticles and its antidermatophytic activity. Spectrochim Acta Part A 124: 194-198.

25. Ajitha B, Ashok Kumar Reddy Y, Shameer S, Rajesh KM, Suneetha Y, et al (2015) Lantana camara leaf extract mediated silver nanoparticles: Antibacterial, green catalyst. J Photochem and Photobiology B 149: 84-92.

26. Devika R, Elumalai S, Manikandan E, Eswaramoorthy D (2012) Biosynthesis of Silver Nanoparticles Using the Fungus Pleurotus ostreatus and their Antibacterial Activity. 1: 12.

27. Bindhu MR, Umadevi M (2015) Antibacterial and catalytic activities of green synthesized silver nanoparticles. Spectrochim Acta Part A 135: 373-378.

28. Narayanan KB, Sakthivel N (2011) Extracellular synthesis of silver nanoparticles using the leaf extract of Coleus amboinicus Lour. Materials Research Bulletin 46: 1708-1713.

29. Petla RK, Vivekanandhan S, Misra M, Mohanty A, Satyanarayana N (2012) Soybean (Glycine Max) Leaf Extract Based Green Synthesis of Palladium Nanoparticles J Biomater Nanobiotech 3: 14-19.

30. Ajitha B, Ashok Kumar Reddy Y, Sreedhara Reddy P (2015) Green synthesis and characterization of silver nanoparticles using Lantana camara leaf extract. Mater Sci Engg C 49: 373-381.

31. He S, Yao J, Jiang P, Shi D, Zhang H, et al. (2001) Formation of Silver Nanoparticles and Self-Assembled Two-Dimensional Ordered Superlattice. Langmuir 17: 1571-1575.

32. Xu J, Han X, Liu H, Hu Y (2006) Synthesis and optical properties of silve nanoparticles stabilized by gemini surfactant. Colloids and Surfaces A Physicochem. Eng. Aspects 273: 179-183.

33. Zhao Y, Jiang Y, Fang Y (2006) Spectroscopy property of Ag nanoparticles. Spectrochim Acta A Mol Biomol Spectrosc 65: 1003-1006.

34. Beversluis MR, Bouhelier A, Novotny L (2003) Continuum generation from single gold nanostructures through near-field mediated intraband transitions. Physical Review B 68: 115433.

35. Basavegowda N, Idhayadhulla A, Lee YR (2014) Preparation of Au and Ag nanoparticles using Artemisia annua and their in vitro antibacterial and tyrosinase inhibitory activities. Mater Sci Eng C Mater Biol Appl 43: 58-64.

36. Sadeghi B, Rostami A, Momeni SS (2015) Facile green synthesis of silver nanoparticles using seed aqueous extract of Pistacia atlantica and its antibacterial activity. Spectrochim Acta Part A 134: 326-332.

37. Sankar R, Karthik A, Prabu A, Karthik S, Shivashangari KS, Ravikumar V (2013) Origanum vulgare mediated biosynthesis of silver nanoparticles for its antibacterial and anticancer activity. Colloids Surf B 108: 80- 84 
Citation: Anandalakshmi K, Venugobal J (2017) Green Synthesis and Characterization of Silver Nanoparticles Using Vitex negundo (Karu Nochchi) Leaf Extract and its Antibacterial Activity. Med Chem (Los Angeles) 7: 218-225. doi: 10.4172/2161-0444.1000460

38. Achari B, Chowdhuri US, Dutta PK, Pakrashi SC (1984) Two Isomeric Flavones from Vitex negundo. Phytochemistry 23: 703-704.

39. Banerji J, Das B, Chakrabarty R, Jha H (1988) Isolation of 4, 4'-dimethoxytrans-stilbene \& flavonoids from leaves \& twigs of Vitex negundo Linn. Indian J Chem Sect B 27: 597.

40. Subramanian PM, Misra GS (1979) Flavonoids of Vitex negundo J. Nat. Products 42: 540-542.

41. Dutta PK, Chowdhury US, Chakravarty AK, Achari B, Pakrashi SC (1983) Studies on indian medicinal plants-part LXXV: Nishindaside, a novel iridoid glycoside from Vitex negundo. Tetrahedron 39: 3067-3072.

42. Sehgal CK, Taneja SC, Dhar KL, Atal CK (1982) '2'-p-hydroxybenzoyl mussaenosidic acid a new iridoid glucoside from Vitex negundo. Phytochemistry 21: 363-366.

43. Sehgal CK, Taneja SC, Dhar KL, Atal CK (1983) '6'-p-hydroxybenzoy mussaenosidic acid an iridoid glucoside from Vitex negundo. Phytochemistry 22: $1036-1038$

44. Chawla AS, Sharma AK, Handa SS, Dhar KL (1992) Chemical investigation and anti-inflammatory activity of Vitex negundo seeds. J Nat Prod 55: 163-167.

45. Rimando AM, Inoshiri S, Otsuka H, Kohda H, Yamasaki K, Padolina WG, Torres L, Quintana EG, Cantoria MC (1987) Screening for mast cell histamine release inhibitory activity of Philippine medicinal plants active constituent of Ehretia microphylla. Shoyakugaku Zasshi 41: 242-247.

46. Mukherjee KS, Badruddoza S (1981) Chemical constituents of Dillenia indica Linn. and Vitex negundo Linn. J Indian Chem Soc 58 97-98.

47. Elumalai K, Velmurugan S (2015) Green synthesis, characterization and antimicrobial activities of zincoxide nanoparticles from the leaf extract of Azadirachta indica (L.) Applied Surface Science 345: 329-336.

48. Ajitha B, Ashok Kumar Reddy Y, Sreedhara Reddy P (2014) Biogenic nanoscale silver particles by Tephrosia purpurea leaf extract and their inborn antimicrobial activity. Spectrochim Acta Part A 21: 164-172.

49. Noruzi M, Zare D, Khoshnevisana K, Davoodi D (2011) Rapid green synthesis of gold nanoparticles using Rosa hybrida petal extract at room temperature. Spectrochim Acta Part A 79: 1461-1465.

50. Kalpana D, Soo Lee Y (2013) Synthesis and characterization of bactericidal silver nanoparticles using cultural filtrate of simulated microgravity grown Klebsiella pneumoniae. Enzyme and Microbial Technology 52: 151-156.
51. Raja K, Saravanakumar A, Vijayakumar R (2012) Efficient synthesis of silver nanoparticles from Prosopis juliflora leaf extract and its antimicrobial activity using sewage. Spectrochim Acta Part A 97: 490-494.

52. Kumar R, Mohana Roopan S, Prabhakarn A, Khanna VG, Chakroborty S (2012) Agricultural waste Annona squamosa peel extract: Biosynthesis of silver nanoparticles. Spectrochim Acta Part A 90: 173-176.

53. Jayaseelan C, Ramkumar R, Rahuman AA, Perumal P (2013) Green synthesis of gold nanoparticles using seed aqueous extract of Abelmoschus esculentus and its antifungal activity. Ind Crops Prod 45: 423-429.

54. Shankar SS, Rai A, Ahmad A, Sastry M (2004) Rapid synthesis of Au, Ag and bimetallic Au core-Ag shell nanoparticles using Neem (Azadirachta indica) leaf broth. Journal of Colloids and interface Science 275: 496-502.

55. Magudapathy Z, Gangopadhyay P, Panigrahi BK, Nair KGM, Dhara S (2001) Electrical transport studies of $\mathrm{Ag}$ nanoclusters embedded in glass matrix. Physica B: Cond Matt 299: 142-146.

56. Mollick MR, Rana D, Dash SK, Chattopadhyay S, Bhowmick B, et al. (2015) Studies on green synthesized silver nanoparticles using Abelmoschus esculentus (L.) pulp extract having anticancer (in vitro) and antimicrobial applications. Arabian journal of chemistry 5.

57. Samy MS (2016) Studying the effect of newly synthesized cationic surfactant on silver nanoparticles formation and their biological activity. J Mole Liq 216 : 137-145.

58. Shaban SM, Aiad I, El-Sukkary MM, Soliman EA, El-Awady MY (2014) One step green synthesis of hexagonal silver nanoparticles and their biological activity. Journal of Industrial and Engineering Chemistry 20: 4473-4481.

59. Mehmood A, Murtaza G, Bhatti TM, Kausar R (2013) Phyto-mediated synthesis of silver nanoparticles from Melia azedarach L. leaf extract: Characterization and antibacterial activity. Arabian Journal of Chemistry 28.

60. Zhang Y, Cheng X, Zhang Y, Xue X, Fu Y (2013) Biosynthesis of silver nanoparticles at room temperature using aqueous aloe leaf extract and antibacterial properties. Colloids and Surfaces A: Physicochem. Eng. Aspects 423: 63-68.

61. Ruparelia JP, Chatterjee AK, Duttagupta SP, Mukherji S (2008) Strain specificity in antimicrobial activity of silver and copper nanoparticles. Acta Biomater. 4 707-716. 